\title{
BMJ Open Impact of non-menthol flavours in e-cigarettes on perceptions and use: an updated systematic review
}

\author{
Clare Meernik, ${ }^{1}$ Hannah M Baker, ${ }^{2,3}$ Sarah D Kowitt, ${ }^{3}$ Leah M Ranney, ${ }^{3}$ \\ Adam O Goldstein ${ }^{2,3}$
}

To cite: Meernik C, Baker HM, Kowitt SD, et al. Impact of non-menthol flavours in e-cigarettes on perceptions and use: an updated systematic review. BMJ Open 2019;9:e031598. doi:10.1136/ bmjopen-2019-031598

- Prepublication history and additional material for this paper are available online. To view please visit the journal (http:// dx.doi.org/10.1136/bmjopen2019-031598).

$\mathrm{CM}$ and $\mathrm{HMB}$ are joint first authors.

Received 10 May 2019

Revised 05 September 2019

Accepted 06 September 2019

Check for updates

(c) Author(s) (or their employer(s)) 2019. Re-use permitted under CC BY-NC. No commercial re-use. See rights and permissions. Published by BMJ.

${ }^{1}$ Epidemiology, University of North Carolina at Chapel Hill, Chapel Hill, North Carolina, USA ${ }^{2}$ Lineberger Comprehensive Cancer Center, University of North Carolina at Chapel Hill, Chapel Hill, North Carolina, USA

${ }^{3}$ Family Medicine, University of North Carolina at Chapel Hill, Chapel Hill, North Carolina, USA

Correspondence to

Dr Adam 0 Goldstein;

adam_goldstein@med.unc.edu

\section{ABSTRACT}

Objectives Given the exponential increase in the use of e-cigarettes among younger age groups and in the growth in research on e-cigarette flavours, we conducted a systematic review examining the impact of non-menthol flavoured e-cigarettes on e-cigarette perceptions and use among youth and adults.

Design PubMed, Embase, PyscINF0 and CINAHL were systematically searched for studies published and indexed through March 2018.

Eligibility criteria Quantitative observational and experimental studies that assessed the effect of nonmenthol flavours in e-cigarettes on perceptions and use behaviours were included. Specific outcome measures assessed are appeal, reasons for use, risk perceptions, susceptibility, intention to try, initiation, preference, current use, quit intentions and cessation.

Data extraction and synthesis Three authors independently extracted data related to the impact of flavours in tobacco products. Data from a previous review were then combined with those from the updated review for final analysis. Results were then grouped and analysed by outcome measure.

Results The review included 51 articles for synthesis, including 17 published up to 2016 and an additional 34 published between 2016 and 2018. Results indicate that non-menthol flavours in e-cigarettes decrease harm perceptions (five studies) and increase willingness to try and initiation of e-cigarettes (six studies). Among adults, e-cigarette flavours increase product appeal (seven studies) and are a primary reason many adults use the product (five studies). The role of flavoured e-cigarettes on smoking cessation remains unclear (six studies). Conclusion This review provides summary data on the role of non-menthol flavours in e-cigarette perceptions and use. Consistent evidence shows that flavours attract both youth and adults to use e-cigarettes. Given the clear findings that such flavours increase product appeal, willingness to try and initiation among youth, banning non-menthol flavours in e-cigarettes may reduce youth e-cigarette use. Longitudinal research is needed to examine any role flavours may play in quit behaviours among adults.

\section{INTRODUCTION}

Despite a ban on non-menthol flavours in cigarettes, current regulations in the USA

\section{Strengths and limitations of this study}

- This large comprehensive review included 51 final articles for synthesis, including 17 published up to 2016 and an additional 34 published between 2016 and 2018.

- The majority of studies were cross-sectional and were from convenience samples, limiting the ability to make causal inferences as well as the generalisability of findings from these articles.

- We used a quality assessment tool (QATSDD) to rate the quality of articles included in the review.

- Qualitative data, while excluded, could have provided additional contextual information to the conclusions.

allow for the sale of non-menthol flavours in other tobacco products, including e-cigarettes. ${ }^{1}$ However, the US Food and Drug Administration (FDA) continues to seek out and prioritise research that explores the issue of non-menthol flavours in tobacco products other than cigarettes and as such has issued an advance notice of proposed rulemaking seeking comments on the role that flavours play in tobacco product use. ${ }^{2}$ Similarly, in fall of 2018, the FDA proposed a policy framework that would only allow non-menthol flavoured e-cigarettes to be sold in age-restricted locations or online under heightened age verification standards. ${ }^{3}$

Some studies have shown that flavours are particularly appealing to youth and are cited as a primary reason for use among this age group. ${ }^{4}$ The use of e-cigarettes among youth may be a gateway to future cigarette use, ${ }^{56}$ and nicotine (which is found in most e-cigarettes) is especially harmful to developing adolescent brains. ${ }^{7-9}$ This makes the recent precipitous increase in e-cigarette use among youth particularly alarming. ${ }^{7}$ Policymakers, including the FDA, are increasingly concerned about the rise in popularity of pod-type e-cigarette devices (eg, Juul), which 
now own a large market share and deliver more nicotine than older generations of e-cigarettes. ${ }^{10} 11$

E-cigarettes are also regarded by many experts in tobacco control as a potential means of harm reduction among adult smokers if they use e-cigarettes to transition away from combustible tobacco products. ${ }^{12} \mathrm{~A}$ few studies have suggested a positive association between e-cigarettes and quitting behaviours, including a recent randomised controlled trial. ${ }^{13-16}$ Unravelling the relationship between potential harms or benefits of e-cigarette use among adult smokers is important in the development of regulations for e-cigarettes and, in particular, regulations regarding product flavours.

It is well known that recent years have seen a precipitous increase in the use of e-cigarettes in the USA and other countries among both youth and adults. ${ }^{17}$ Recent data suggest that $20.8 \%$ of US youth ${ }^{18}$ and $4.5 \%$ of US adults are current e-cigarette users. ${ }^{19}$ These numbers vary globally, with $5.9 \%$ of adults and $8.2 \%$ of adolescents in Poland but only $0.3 \%$ of adults in Indonesia reporting current use. ${ }^{20}$ However, upward trajectories of use have been noted globally, ${ }^{20}$ and this increase in use has coincided with an exponential rise in e-cigarette flavours, with over 7000 flavours existing. ${ }^{21}$ Many of these flavours utilise names that may appeal to younger populations such as cotton candy, gummy bear, cookies ' $\mathrm{n}$ cream and other sweet-flavoured brands. ${ }^{21}$ The intense public health interest in e-cigarettes' impact on the tobacco control landscape and population health has resulted in a sharp increase in research conducted on flavours and e-cigarettes. Given this changing landscape, we conducted a systematic review of non-menthol flavoured e-cigarettes that extends previous research ${ }^{4}$ by providing evidence specific to e-cigarettes about the role of non-menthol flavours in appeal, harm perceptions, intentions, use and cessation among youth and adults in the USA and globally.

\section{METHODS}

We used methods similar to previously published research ${ }^{4}$ and implemented two alterations: (1) updated the range of eligible publication dates (with the original including articles ever published until 4 April 2016, and the current review including articles published and indexed on or after 4 April 2016), and (2) focused this review specifically on e-cigarettes rather than all tobacco products, based on the precipitous increase in literature on e-cigarettes, as well as the increase in use of these products among youth and adults. All data relevant to the study are included in the article or uploaded as online supplementary information.

\section{Eligibility criteria}

We included observational and experimental studies that assessed the impact of non-menthol flavours in e-cigarettes on perceptions and use behaviours such as initiation, preference and cessation. We did not exclude studies based on participant characteristics. Studies included populations of any age, race, sex, ethnicity or country.

We excluded the following types of articles: those that were not English-language; were not peer-reviewed (eg, dissertations, technical reports); did not contain original data about flavoured e-cigarettes (eg, editorials, commentaries, literature reviews); did not address the impact of flavours on e-cigarette perceptions and use behaviours (eg, biological/medical/chemical toxicology/animal studies, sales trends, effects of flavour bans); were related to smoking marijuana or limited findings to menthol flavoured e-cigarettes only. In order to maintain a semblance of consistency across studies examined, we chose to exclude articles that used qualitative study designs. Additionally, because menthol and tobacco are often treated differently as it relates to policy implementation (eg, in 2009, FDA banned characterising flavours except for tobacco and menthol in cigarettes) and is also often viewed separately from other flavours in the literature, this review excludes articles that examine just menthol as a flavour. ${ }^{22}$ We do include tobacco flavor in this review because despite the regulatory differences, some literature chooses to include tobacco as a characterising flavour and we wanted to explore any potential relationships produced by the literature.

\section{Type of outcome measures and intervention}

Outcome measures include perceptions about appeal, reasons for use and risk perceptions; susceptibility and intentions to try and use behaviours, including initiation, preference, current use, quit intentions and cessation.

\section{Data sources and study selection \\ Literature search}

One author (HMB) conducted searches of PubMed, Embase, PsycINFO and CINAHL for studies published and indexed in a database between 4 April 2016 and 12 March 2018. To maintain consistency with the previous systematic review, we maintained the same search string rather than modifying the search to include only e-cigarettes. We used Boolean language to connect variants of words related to tobacco products, use and flavour for PubMed, which was translated to match the search string requirements for other databases. A total of 3191 articles resulted from searching the four databases during the initial search (21 March 2018). After authors removed duplicates, 2822 articles remained for title and abstract review, including 14 articles identified through manual search of references.

\section{Study selection}

Two authors (CM and HMB) reviewed the titles and abstracts of all 2822 articles. A third author (SK) resolved any discrepancies. Following this step, two authors (CM and HMB) reviewed the full text of all 114 articles eligible for full-text screening. A third author (SK) resolved any discrepancies. Eighty articles were excluded for the following reasons: they did not have data on the 


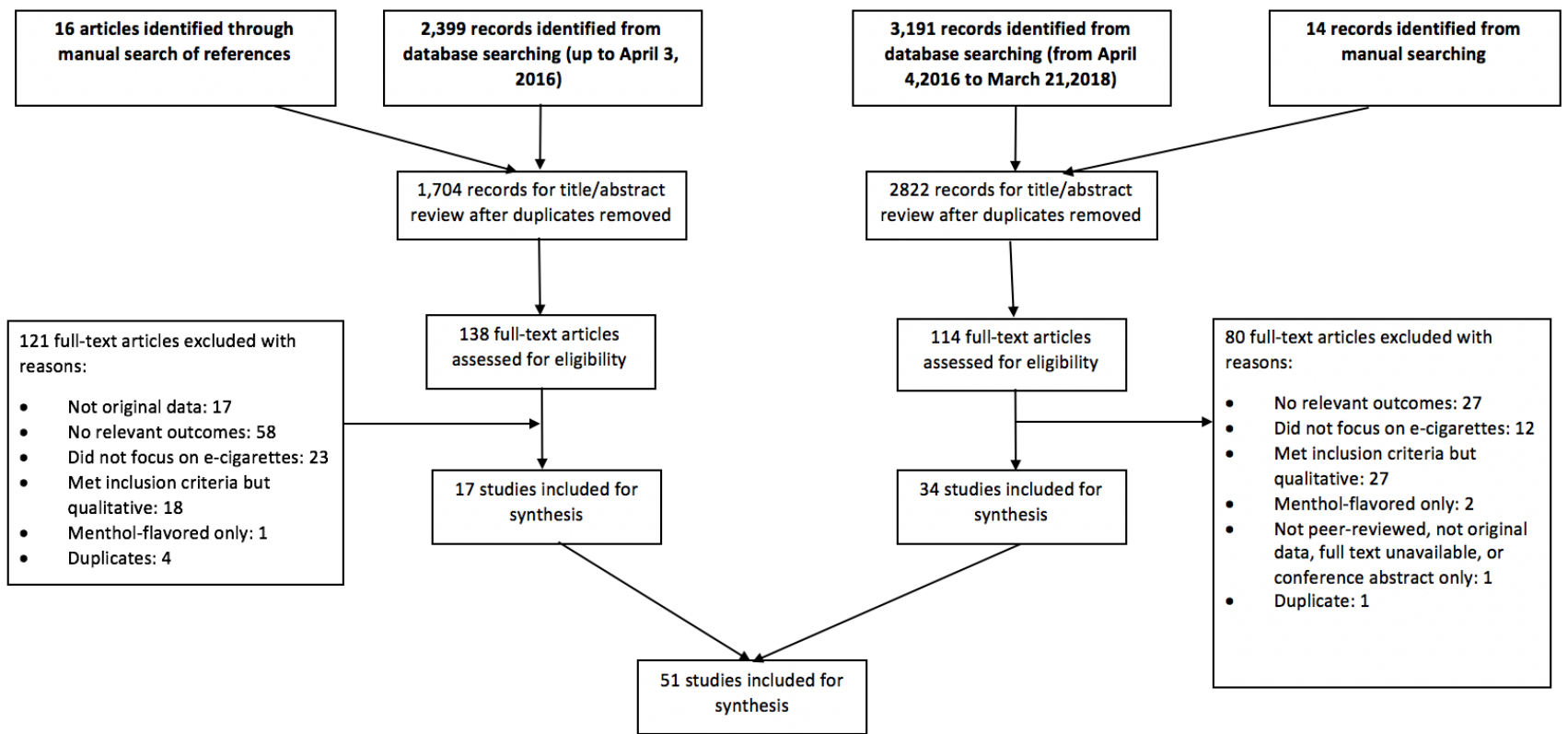

Figure 1 Preferred Reporting Items for Systematic Reviews and Meta-Analyses (PRISMA) flow diagram.

specified outcomes $(\mathrm{n}=27)$, used qualitative methodologies $(n=27)$, focused on a tobacco product other than e-cigarettes $(n=12)$, were only focused on menthol flavour $(\mathrm{n}=2)$, was a duplicate $(\mathrm{n}=1)$ or were not peer-reviewed, did not include original data, did not include full-text or included only a conference abstract $(n=11)$. Articles that addressed e-cigarettes from the original systematic review $(n=17)$ were then added to the 34 articles identified from this current review, combining for a total of 51 articles included in the final analysis. The study selection processes, which approximate but do not exactly follow the Preferred Reporting Items for Systematic Reviews and Meta-Analyses (PRISMA) methodology, are illustrated in figure $1 .^{23}$

\section{Data extraction and synthesis}

For the articles identified in the most current review, three authors (CM, HMB, SK) independently extracted data using a data extraction sheet, which assessed study aim, type of flavoured tobacco product, characteristics of study populations and study design, and main results and findings related to the impact of flavours in tobacco products. We used a validated quality assessment tool (QATSDD) to examine the quality of quantitative studies with a diverse range of research designs. ${ }^{24}$ Studies were scored on a 4-point scale from 0 (did not address criteria at all) to 3 (completely addressed criteria), with specified guidance to inform scorers based on the level of detail provided by study authors. ${ }^{24}$ Specific scores were not used for inclusion/exclusion or used in any analysis. Rather, the tool was used to provide a valuable overall assessment of the general quality of included studies from which our conclusions are based. To ensure agreement in data extraction and quality assessment, three authors (CM, HMB, SK) reviewed and extracted the same three articles, then compared results of review and extraction, resolving discrepancies through an iterative approach of discussion. Once mutual standards were decided upon based on this process, each of the three authors then split up the remainder of articles to extract and assess on their own. We created evidence tables using pertinent information extracted from each study, and we grouped the results by outcome measures. A similar procedure was conducted in the previous review, and all data were combined for final data analysis. A meta-analysis was not conducted due to the heterogeneity in outcomes across studies.

\section{Patient and public involvement}

This research did not include input from patients or the public.

\section{RESULTS}

The review included 51 final articles for synthesis, including 17 published up to 2016 and 34 published between 2016 and 2018. Most studies included adults only $(n=30)$, though 13 included youth and 8 included both youth and adults (table 1 ).

Results of this review are broken out into three age categories: youth, adults, and youth and adults combined. Studies defined these age groups differently, and we therefore used the age groups as defined by the study authors. Most youth were defined as anyone below age 18 years (though some went up to age 19 years ${ }^{25}$ ), and most adults were defined as $18+$ years. Additionally, though young adults are an important population and were included as 
Table 1 Characteristics of included studies $(n=51)$

\begin{tabular}{|c|c|c|c|c|}
\hline Sample characteristics & & $\mathbf{N}(\%)$ & $\begin{array}{l}\text { US studies } \\
(n=37), \\
N(\%)\end{array}$ & $\begin{array}{l}\text { International } \\
\text { studies }(n=14) \text {, } \\
N(\%)\end{array}$ \\
\hline \multirow[t]{3}{*}{ Population } & Youth only & $13(25)$ & $9(24)$ & $4(29)$ \\
\hline & Adults only & $30(59)$ & $22(59)$ & $8(57)$ \\
\hline & Both youth and adults & $8(16)$ & $6(16)$ & $2(14)$ \\
\hline Design & Cross-sectional & $47(92)$ & $33(89)$ & $14(100)$ \\
\hline \multirow[t]{2}{*}{ Sampling (not mutually exclusive) } & Convenience & $35(69)$ & $23(62)$ & $12(86)$ \\
\hline & Probability & $19(37)$ & $17(46)$ & $2(14)$ \\
\hline \multirow{4}{*}{$\begin{array}{l}\text { Outcome measure (not mutually } \\
\text { exclusive) }\end{array}$} & Taste, appeal, perceived risk & $14(27)$ & $10(27)$ & $4(29)$ \\
\hline & Reasons for use & $13(25)$ & $11(30)$ & $2(14)$ \\
\hline & Current use behaviours & $12(24)$ & $10(27)$ & $2(14)$ \\
\hline & Quit intention/quitting behaviour & $10(20)$ & $7(19)$ & $3(21)$ \\
\hline
\end{tabular}

a separate age group in some studies in the review, the variability in definitions of this age group made it difficult to separate for purposes of the results (some defining as ages 19-34 years, some as ages 18-29 years, etc), and we therefore included all young adults in the adult category. Specific age groups used by authors can be found in table 2.

Seventy-two per cent $(\mathrm{n}=37)$ of included studies were conducted in the USA. While four studies used longitudinal designs, most $(\mathrm{n}=47 ; 92 \%)$ were cross-sectional. Study populations, aims and relevant outcomes are provided in table 2, with more detailed descriptions of analytical methods and results included in online supplementary table 1 .

\section{Taste, appeal and risk perceptions}

Youth

Four studies surveyed probability samples of youth and assessed harm perceptions of e-cigarettes, all observing similar results. Three studies of youth in the USA (two national samples and one state-wide sample) and one national sample of youth in the UK found that perceptions of e-cigarette harm differed depending on the product flavouring. Specifically, fruit and candy-flavoured e-cigarettes were perceived as less harmful than tobacco-flavoured e-cigarettes, ${ }^{26}{ }^{27}$ and ever or current e-cigarette users were less likely than non-users to perceive flavoured e-cigarettes or tobacco as harmful. ${ }^{28} 29$

\section{Adults}

Eight studies were conducted among adults, including three laboratory experiments and one discrete choice experiment that examined the effect of e-cigarette flavours on factors such as ratings of taste and appeal. ${ }^{30-33}$ Four studies included relatively small convenience samples of adults, each finding similar results: flavours in e-cigarettes enhanced the rewarding and reinforcing value of e-cigarettes compared with unflavoured e-cigarettes, ${ }^{30}$ and the appealing sensory characteristics of flavours (ie, sweetness and coolness) were positively associated with liking of the product, ${ }^{32}{ }^{33}$ the willingness to use again and an increase in amount willing to pay for the product. ${ }^{31} 32$ Similarly, in a cross-sectional survey of 765 current or former adult smokers, removal of flavours significantly reduced the price respondents were willing to pay for e-cigarettes, though this association was not observed among dual users of cigarettes and e-cigarettes. ${ }^{34}$ One study in the USA and two international studies likewise found that among ever or current e-cigarette users, the taste and variety of flavours were positive features of e-cigarettes and contributed to increased enjoyment of the product. ${ }^{35-37}$

\section{Youth and adults}

Two studies examined appeal and harm perceptions in convenience samples of youth and adults. A sample of 216 youth and 432 adults in the USA found that adult smokers rated interest toward e-cigarettes significantly higher than non-smoking teens for each e-cigarette flavour examined (note: study was funded by an e-cigarette company) ${ }^{38}$ One discrete choice experiment in Canada $(n=915)$ found that e-cigarette flavour significantly predicted lower perceptions of product harm; specifically, in the overall sample, menthol and coffee flavours were perceived as less harmful; among younger non-smokers, coffee flavour was perceived as less harmful, while younger smokers perceived cherry flavour as less harmful and older smokers perceived tobacco flavour as less harmful. ${ }^{39}$ 


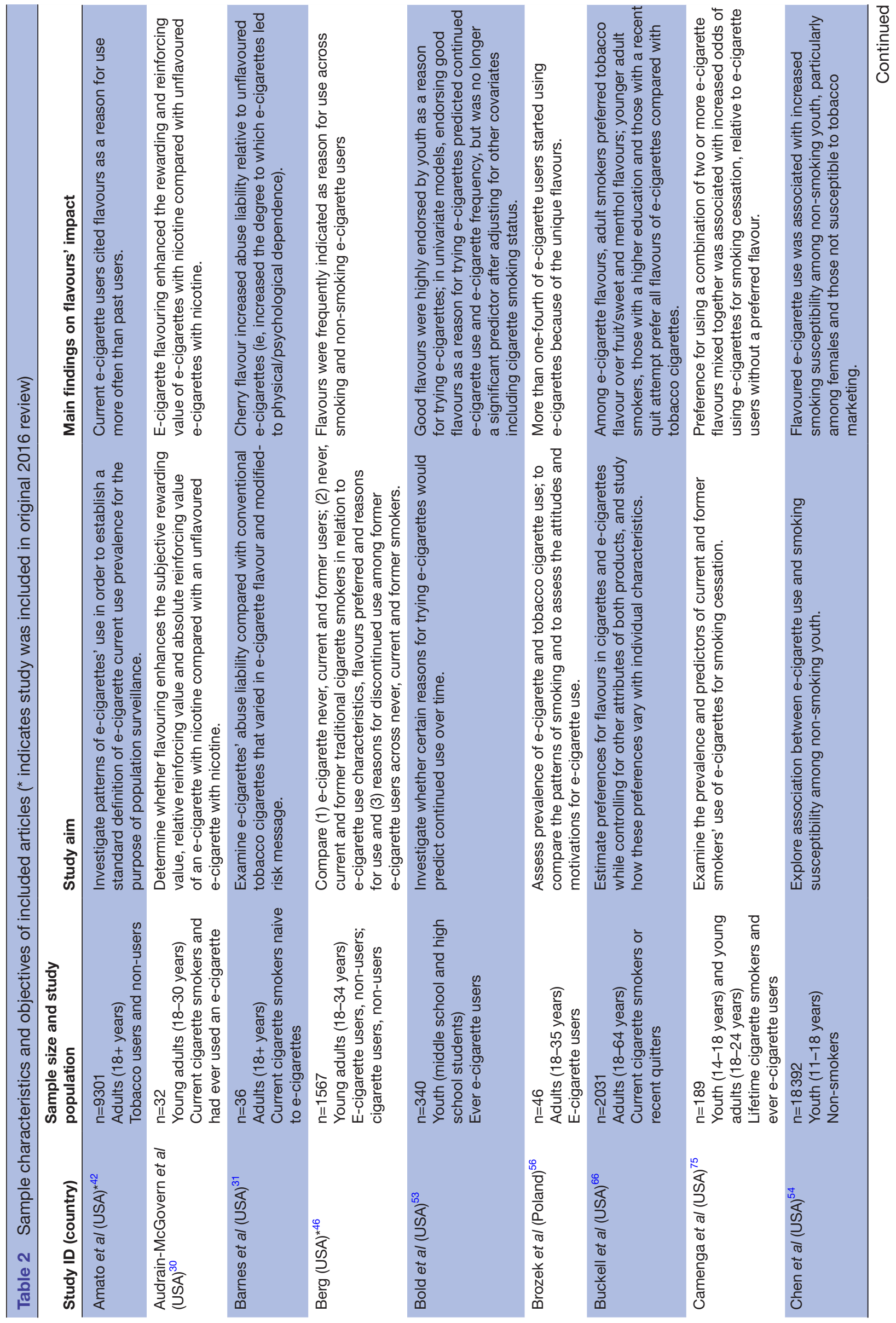

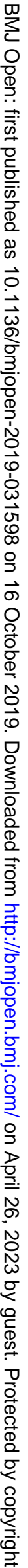




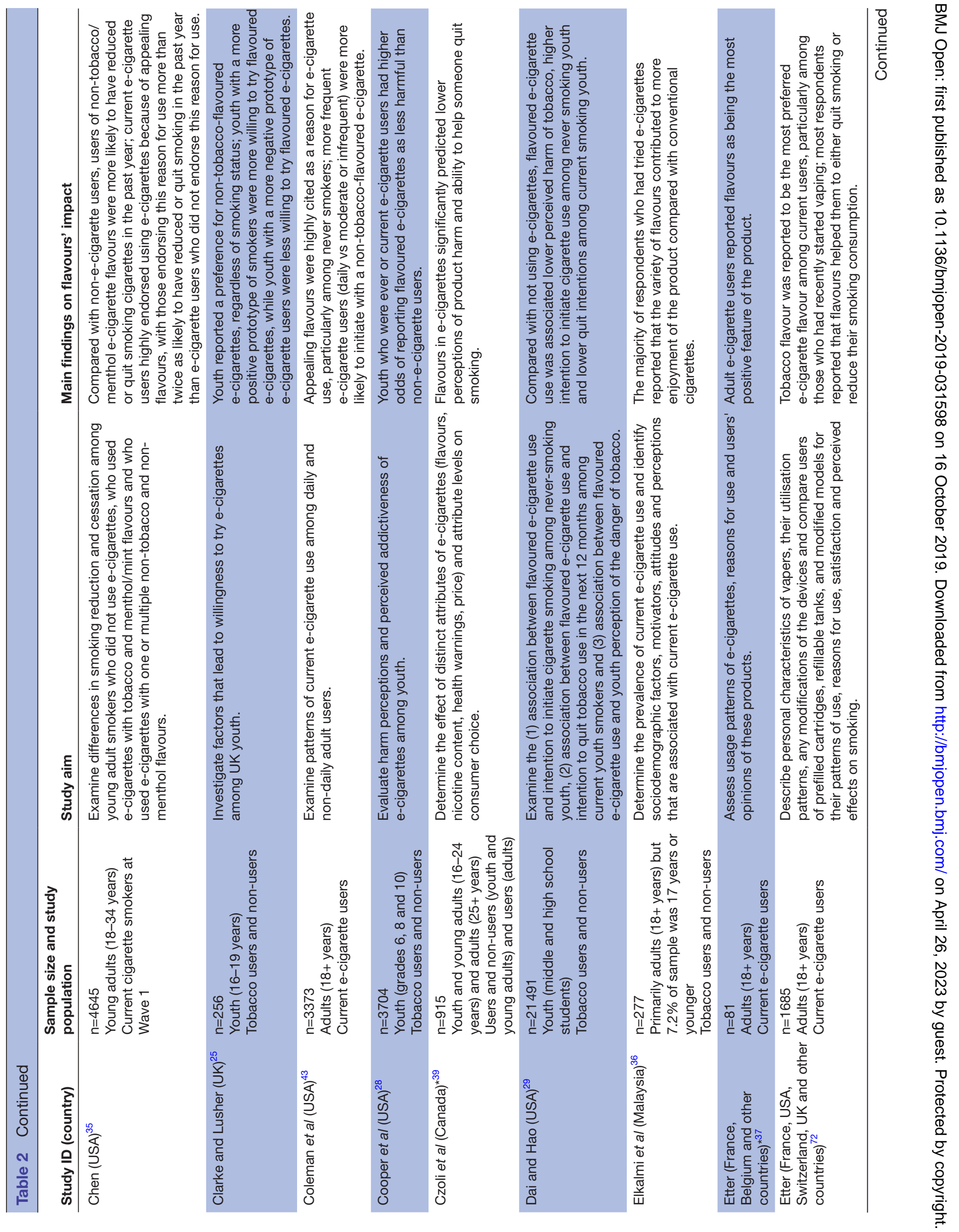




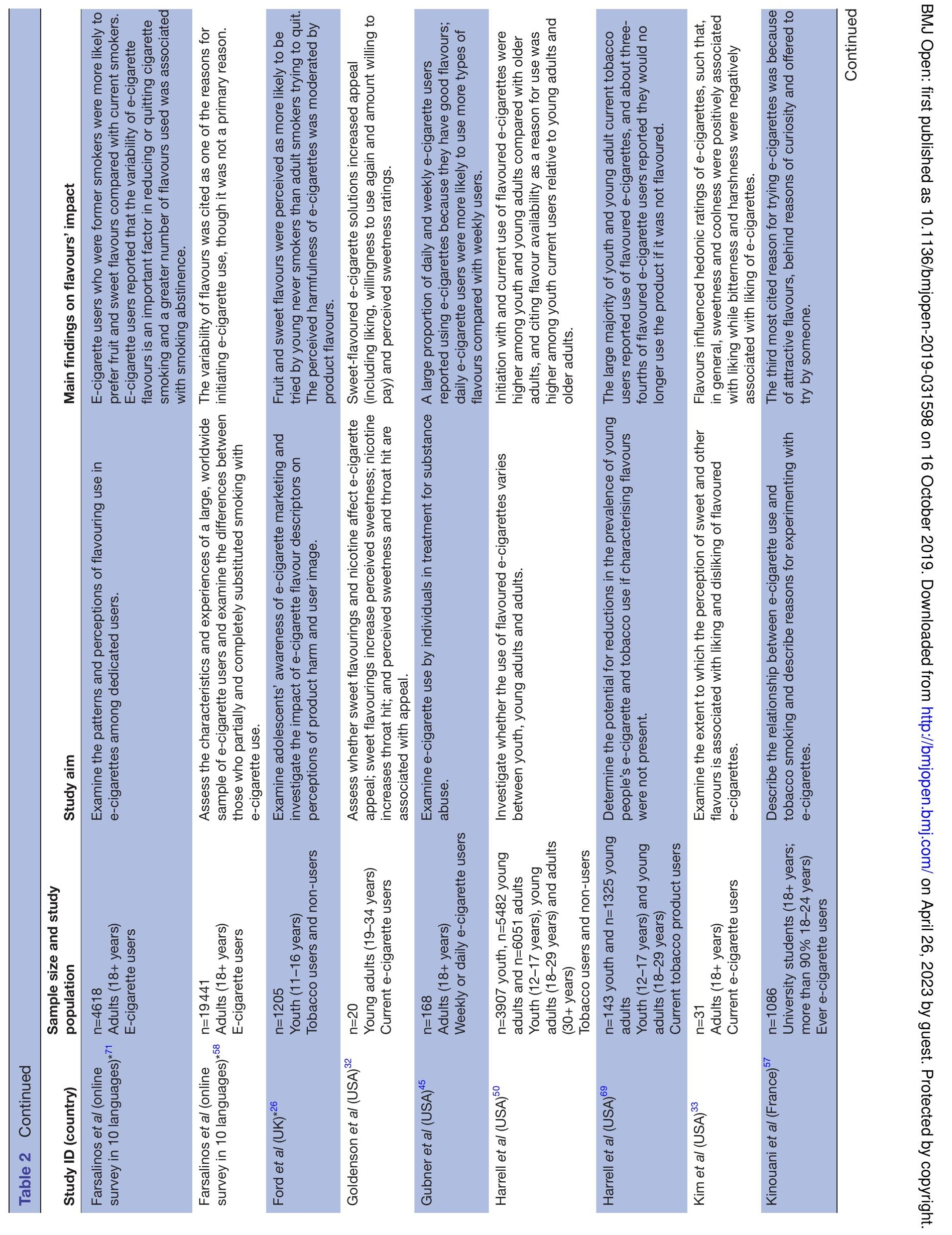




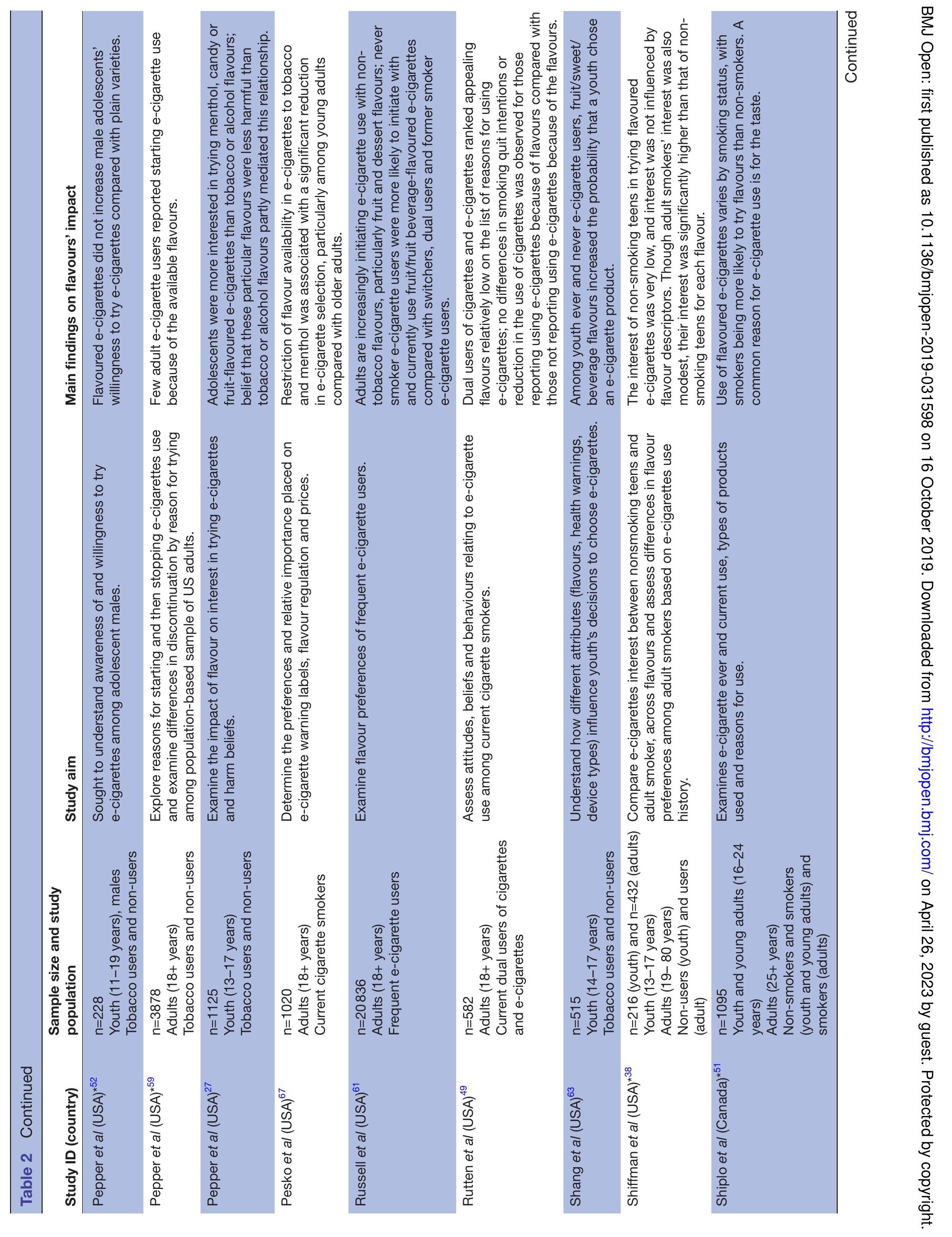




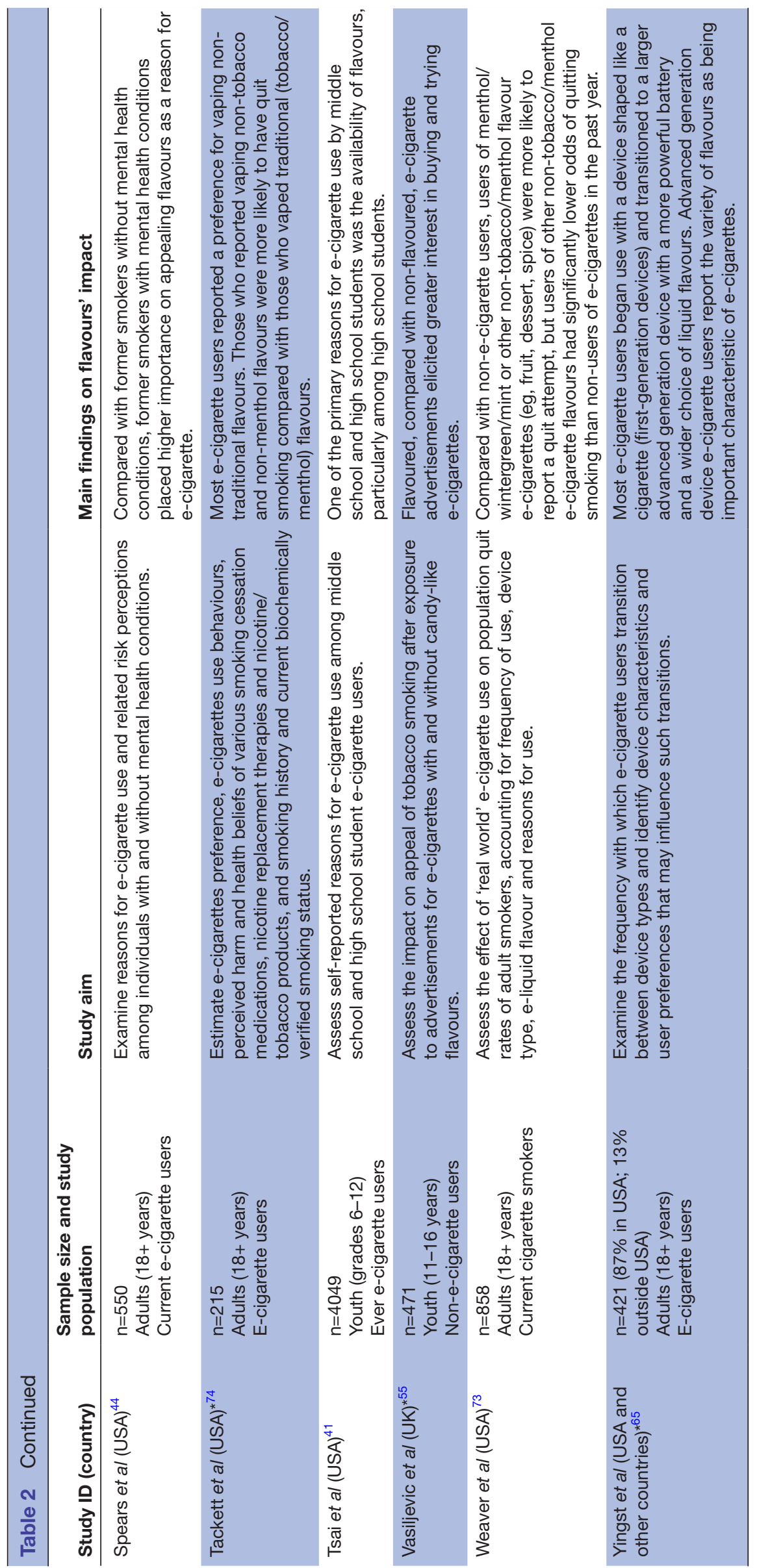




\section{Reasons for use}

Youth

Two national probability samples of youth examining reasons for e-cigarette use found varied results. Less than $10 \%$ of South Korean youth who ever used e-cigarettes reported using the product because of good flavours, ${ }^{40}$ compared with roughly a third of US students reporting ever using e-cigarettes because of the availability of flavours, with high school students more likely than middle school students to report flavours as a reason for use. $^{41}$

\section{Adults}

Nine studies in the USA examined reasons for using e-cigarettes among adults, also finding varied results. Three probability samples (two national and one state-wide) found that a majority of current e-cigarette users cited appealing flavours as a reason for using e-cigarettes, ${ }^{35} 42$ particularly among never cigarette smokers compared with current and former smokers. ${ }^{43}$ Another national probability sample in the USA $(n=550)$ found that former smokers with mental health conditions placed a higher importance on appealing flavours as a reason for use compared with former smokers without mental health conditions. ${ }^{44}$ Further, about $40 \%$ of daily and weekly e-cigarette users $(n=168)$ at substance use treatment centres reported good flavours as a reason for using e-cigarettes. ${ }^{45}$ Among a convenience sample of 1567 young adults, roughly a third of those who were non-e-cigarette users reported appealing flavours as a reason for possible e-cigarette use in the future, while a majority of current e-cigarette users reported appealing flavours and the ability to experiment with a variety of flavours as reasons for use. ${ }^{46}$ Three other studies in the USA (two national probability samples and one small convenience sample) observed relatively low proportions of current adult e-cigarette users reporting using e-cigarettes because of product flavourings, behind a variety of other reasons for use, ${ }^{47-49}$ though flavours were more likely to be cited as a reason for use among younger age groups, particularly young adults aged 18-24 years, and among users of tank devices compared with disposables. ${ }^{48}$

\section{Youth and adults}

Two studies in the USA and Canada among youth and adults found that citing flavour availability or taste as a reason for e-cigarette use was higher among younger e-cigarette users compared with older users. ${ }^{50} 51$

\section{Susceptibility, intention to try and initiation \\ Youth}

Seven studies in the USA and the UK examined susceptibility, intention to try or initiation of e-cigarettes among youth. One study of a national probability sample of 228 adolescent males in the USA found no differences in willingness to try flavoured e-cigarettes compared with plain e-cigarettes. ${ }^{52}$ However, the other six studies reported positive associations between flavours and e-cigarette use intentions. In a convenience sample of 340 youth in the USA who were ever e-cigarette users, more than $40 \%$ endorsed good flavours as a reason for first trying e-cigarettes, the second highest endorsed reason. ${ }^{53}$ Similarly, in a convenience sample of 256 UK youth, cigarette smokers and non-smokers were more willing to try flavoured e-cigarettes than tobacco-flavoured e-cigarettes ( $90 \%$ vs $73 \%$ and $34 \%$ vs $12 \%$, respectively); further, having a positive prototype of smokers was associated with increased willingness to try flavoured e-cigarettes. ${ }^{25}$ Three different studies using national probability samples of US youth found similar relationships between flavours and e-cigarette use susceptibility and intentions to use. Adolescents were more likely to try menthol-flavoured, candy-flavoured or fruit-flavoured e-cigarettes compared with tobacco-flavoured e-cigarettes ${ }^{27}$; and flavoured e-cigarette use among non-smoking youth was associated with increased intention to initiate cigarette use ${ }^{29}$ and smoking susceptibility, particularly among females and those not susceptible to tobacco marketing. ${ }^{54}$ Finally, a convenience sample of 471 non-e-cigarette using youth in the UK found that exposure to flavoured e-cigarette ads, compared with non-flavoured e-cigarette ads, increased interest in buying and trying e-cigarettes. ${ }^{55}$

\section{Adults}

Six studies conducted in the USA and internationally examined intention to try or initiation of e-cigarettes among adults. Two studies using convenience samples of young adults in Poland $(n=46)$ and France $(n=1086)$ both found that roughly $25 \%-30 \%$ of e-cigarette users tried or started using e-cigarettes because of the variability of flavours, though other reasons for initiation were rated more highly than flavours. ${ }^{565}$ Similarly, among an online convenience sample of international e-cigarette users ( $n=19441)$ (note: study was funded by an e-cigarette advocacy group) and among a combined probability and non-probability sample of US adults $(n=3878)$, the availability of appealing flavours was not frequently cited as a reason for e-cigarette initiation. ${ }^{5859}$ However, two convenience samples of US adults found that the availability of flavours in e-cigarettes was associated with increased intention to use the product among young adult college students, ${ }^{60}$ and never smoker e-cigarette users were more likely to have initiated e-cigarette use with a fruit-flavoured product compared with switchers (from regular cigarette smoking to regular e-cigarette use), dual users and former smoker e-cigarette users. ${ }^{61}$

\section{Youth and adults}

Four studies examined interest in trying and initiation of e-cigarettes among youth and adults. One study of 648 youth and adults in the USA observed that adult smokers' interest in trying e-cigarettes was significantly higher than non-smoking teens' interest for all 15 e-cigarette flavours investigated (note: study was funded by an e-cigarette company). ${ }^{38}$ However, the three other studies conducted found similar results, in that youth and younger adults 
in Canada expressed more interest in trying non-tobacco-flavoured e-cigarettes than older adults ${ }^{39}$; high school students in the USA were more likely to experiment with e-cigarettes because of flavours compared with college students, with $40 \%$ of the overall sample $(n=1157)$ reporting the availability of flavours as a reason for experimentation with e-cigarettes ${ }^{62}$; and youth and young adults reported higher initiation with flavoured e-cigarette use compared with tobacco-flavoured e-cigarettes. ${ }^{50}$

\section{Preference}

Youth

In three studies of youth, one discrete choice experiment of 515 e-cigarette ever and never users in the USA found that fruit, sweet and beverage flavours increased the probability (relative to tobacco flavour) of choosing an e-cigarette product. ${ }^{63}$ A national probability sample of 1205 UK youth examined how youth perceive others to use e-cigarettes; youth perceived adult smokers who were trying to quit smoking as less likely to prefer cherry, candy floss or coffee flavoured e-cigarettes, whereas youth perceived adolescents their age to be more likely to try flavoured e-cigarettes compared with tobacco-flavoured ${ }^{26}$ Further, a convenience sample of 4780 middle school and high school students in the USA found that most ever e-cigarette users-regardless of cigarette smoking statushad tried and preferred sweet flavours compared with menthol and tobacco flavours. ${ }^{64}$

\section{Adults}

Four studies examined preference among adults in relation to e-cigarette flavours. One international study of 421 e-cigarette users found that those using an advanced generation e-cigarette device were more likely to rate a variety of flavour choices as important, relative to users of first-generation devices. ${ }^{65} \mathrm{~A}$ laboratory experiment of a small convenience sample of adults in the USA observed that ever e-cigarette users took twice as many puffs from flavoured e-cigarettes compared with unflavoured e-cigarettes. ${ }^{30}$ Further, a discrete choice experiment of 2031 adults in the USA found that adult smokers preferred tobacco-flavoured e-cigarettes to fruit/sweet and menthol flavours, ${ }^{66}$ while another discrete choice experiment of 1020 adults observed that increased flavour availability increased e-cigarette selection for younger cigarette smokers but not for older smokers. ${ }^{67}$ Additionally, regardless of interest in quitting cigarettes, greater flavour availability increased e-cigarette selection. ${ }^{67}$

\section{Youth and adults}

Two convenience samples of US youth and adults found that, compared with adult e-cigarette users, adolescent users were more likely to prefer e-cigarette flavours such as fruit and alcohol, while adults were more likely to prefer tobacco, menthol/mint, coffee and spice flavours; further, adult users preferred a greater number of e-cigarette flavours than adolescents. ${ }^{68}$ Among 1468 youth and young adults currently using tobacco, most reported use of flavoured e-cigarettes, and roughly three-quarters of those reported they would not use e-cigarettes if they were not available in a flavoured form, such as candy, fruit or mint/menthol. ${ }^{69}$

\section{Current use behaviours}

Youth

Two studies among US youth examined e-cigarette use behaviours. In a longitudinal study of 340 ever e-cigarette users, youth who initiated e-cigarette use because of good flavours were more frequent users of e-cigarettes, though this association was no longer significant after adjustment for other covariates. ${ }^{53}$ Additionally, in a national probability sample of 18395 never smoking youth, those who used e-cigarettes 3 or more days in the past 30 days were more likely to be flavoured e-cigarette users than those who had used e-cigarettes only 1 or 2 days in the past 30 days. ${ }^{54}$

\section{Adults}

Eight studies among adults examined current e-cigarette use behaviours in relation to flavours. A two-phase longitudinal laboratory study of 88 current cigarette smokers in the USA assigned e-cigarettes to participants as substitution for cigarettes; the highest vaping rates were observed for those assigned to tobacco-flavoured e-cigarettes and the lowest rates were observed for those assigned to chocolate-flavoured. ${ }^{70}$ A convenience sample of 168 e-cigarette users found that daily e-cigarette users reported using more types of flavours and were more likely to have used tobacco flavour or fruit/berry flavour compared with weekly users, ${ }^{45}$ while a national probability sample of 4645 young adults in the USA found that users of non-tobacco/ menthol flavours were more likely to vape daily compared with tobacco-/menthol-flavoured e-cigarette users. ${ }^{35}$ Another national probability sample of 3373 current e-cigarette users in the USA found that daily e-cigarette users were more likely to have initiated with a non-tobacco-flavoured e-cigarette compared with moderate or infrequent e-cigarette users. ${ }^{43}$ A convenience sample of 1185 college students in the USA found that a higher preference for the availability of flavours in e-cigarettes was associated with a higher likelihood of currently using e-cigarettes. ${ }^{60}$ One international survey of 4618 e-cigarette users showed that users who were former smokers were more likely to prefer fruit and sweet flavours compared with current smokers (note: study was promoted by an e-cigarette advocacy group). ${ }^{71}$ Another survey of 1685 e-cigarette users found that tobacco flavour was used by nearly half of the respondents who had started vaping the past 3 months compared with only a quarter of those who had been vaping for at least 4 months. ${ }^{72}$ Lastly, a convenience sample of 20836 frequent e-cigarette users in the USA found that the highest rate of current tobacco-flavoured e-cigarette use was reported by those who initiated e-cigarettes 5 or more years ago, while the lowest rate of tobacco-flavoured e-cigarette use was reported by those who initiated within the past year; those who initiated in 
the past year had the highest rate of fruit, dessert and candy/sweet flavoured e-cigarette use, and never smoker e-cigarette users were more likely to use fruit-flavoured products and less likely to use tobacco-flavoured products compared with ever cigarette smokers. ${ }^{61}$

\section{Youth and adults}

Two studies of youth and adults in the USA reported similar findings related to a preference for flavours among younger e-cigarette users. Nearly all youth and young adult current users (a probability and convenience sample in Texas and nationwide) reported a usual e-cigarette that was flavoured with something other than tobacco (97\%-98\%) compared with roughly $70 \%$ of older adults. ${ }^{50}$ Similarly, a survey of 986 adolescents and adults in the USA found that adolescents who preferred to use fruit, dessert or alcohol-flavoured e-cigarettes reported using e-cigarettes more frequently, and preferring to use a greater number of flavours was associated with using the product more frequently in the past month, though these relationships were not seen among adult e-cigarette users. $^{68}$

\section{Quit intentions and quitting behaviour Youth}

In regards to smoking cessation, one national probability sample of 21491 youth in the USA found that among current smokers, students who reported using flavoured e-cigarettes were less likely to quit tobacco use compared with those who reported not using e-cigarettes or with those who had used non-flavoured e-cigarettes. ${ }^{29}$

\section{Adults}

Seven studies examined the relation between flavours in e-cigarettes and quit intentions and quitting behaviour among adults, finding varied results. One longitudinal study of 4645 young adult cigarette smokers in the USA found that e-cigarette users who used at least one non-to$\mathrm{bacco} /$ menthol flavour were more likely to have reduced or quit smoking cigarettes in the past year compared with non-e-cigarette users, and e-cigarette users who reported using e-cigarettes because of appealing flavours were more than twice as likely to have reduced or quit smoking compared with those who did not endorse using e-cigarettes for that reason. ${ }^{35}$ Another longitudinal study of 858 cigarette smokers in the USA similarly found that users of non-tobacco flavour e-cigarettes (eg, fruit, dessert, spice) were more likely than non-e-cigarette users to report a quit attempt in the past 12 months; however, users of non-tobacco/menthol flavours were less likely to have quit smoking compared with non-e-cigarette users. ${ }^{73}$ In a two-phase longitudinal laboratory study among 88 cigarette smokers, cigarette smoking frequency was most reduced in participants assigned to menthol-flavoured e-cigarettes, while it was least reduced in those assigned to cherry-flavoured or chocolate-flavoured e-cigarettes. ${ }^{70}$ Two international surveys of current e-cigarette users both found that e-cigarette flavours were an important factor in helping to reduce or quit cigarette smoking, ${ }^{71} 72$ and the number of e-cigarette flavours used was associated with smoking abstinence (note: study was promoted by an e-cigarette advocacy group). ${ }^{71}$ Further, a convenience sample of 215 e-cigarette users in the USA found that e-cigarette users reporting use of non-tobacco/menthol flavours were more likely to have quit smoking compared with those vaping tobacco/menthol flavours, ${ }^{74}$ while a national probability sample of 582 dual users in the USA found no differences in smoking quit intentions or smoking reduction for those reporting using e-cigarette because of the flavours compared with e-cigarette users not endorsing use of e-cigarettes for that reason. ${ }^{49}$

\section{Youth and adults}

Two studies among youth and adults examined quit intentions and behaviours. A discrete choice experiment of 915 Canadian tobacco users and non-users observed that menthol-flavoured and coffee-flavoured e-cigarettes were perceived as having a greater quit efficacy. ${ }^{39}$ In a convenience sample of 189 youth and young adult ever e-cigarette users in the USA, preference for using a combination of at least two e-cigarette flavours mixed together was associated with increased likelihood of using e-cigarettes to quit smoking, relative to not having a preferred e-cigarette flavour. ${ }^{75}$

\section{Quality assessment}

We used a validated quality assessment tool (QATSDD) to examine the quality of studies with a diverse range of research designs. ${ }^{24}$ In this quality assessment tool, there are 14 criteria and each criterion is rated on a 4-point scale (0-3), with a maximum score of 42 . Because the studies examined in this review use a variety of methodological approaches, the QATSDD tool was chosen as it was developed specifically for this purpose and has been shown to provide valid, reliable assessments of study quality. ${ }^{24}$ Studies were scored on the criteria listed below, and all scores and criteria can be found in online supplementary table 2. Quality assessment scores relative to the maximum score possible ranged from $38 \%$ to $88 \%$ with a mean score of $66 \%$. Nearly all studies sufficiently detailed their aims and objectives, the research setting, recruitment and data collection, the fit between their research question and method of data collection and analysis, justification for their analytical method, and the study strengths and limitations (see QATSDD scores in online supplementary table 2). However, few studies reported an explicit theoretical framework, user involvement in study design (eg, cognitive interviewing of survey measures), evidence of sample size consideration or statistical assessment of reliability and validity of measurement tools. A low score on these criteria do not necessarily mean that the study authors did not consider it (eg, power calculations that were not reported); rather, the criteria were not sufficiently described in the manuscript. Of note, three studies were funded or promoted by the e-cigarette industry or e-cigarette user advocacy groups. ${ }^{38} 5871$ 


\section{DISCUSSION}

Given the sharp increase in both the use of e-cigarettes (particularly among youth) and the amount of new research related to e-cigarettes and flavours published from 2016 to 2018 alone, this systematic review provides a necessary update of a previous review that included research on e-cigarettes and non-menthol flavours among youth and adults. ${ }^{4}$ This synthesis of evidence regarding the role of non-menthol flavours in e-cigarettes on product perceptions and use is particularly relevant to the FDA's recently proposed policy framework that seeks to place additional regulations on the sale of non-menthol-flavoured e-cigarettes to youth. ${ }^{3}$ Seventeen studies examining flavours in e-cigarettes were published up to 2016; from 2016 to 2018, 34 new studies were published, more than doubling the research in just 2 years.

This new review significantly expands earlier findings about e-cigarettes and flavour among youth and adults. The previous review showed initial evidence that flavours in e-cigarettes were primary reasons for willingness to try or use the products. This expanded systematic review includes emerging longitudinal data and adds evidence on the role of flavours in e-cigarettes among youth and adults. Among youth, flavours increase not only preferences for e-cigarettes but they also increase e-cigarette product appeal, willingness to use, susceptibility to use and initiation, as well as decrease e-cigarette product harm perceptions. Among adults, the expanded research now shows that e-cigarette flavours increase product appeal and enjoyment, and the availability of flavours is a primary reason for use for many adults. Further, our quality review process provides important insight for researchers in this field to improve the rigour of e-cigarette research and includes essential information on study sample size and the reliability or validity of measures.

Findings highlight the following: youth prefer non-tobacco-flavoured e-cigarettes ${ }^{63} 6468$ 69; flavours-particularly sweet flavours such as fruit and candy-decreased perceived product harm ${ }^{26-29} 39$; and the availability of appealing flavours is associated with an increased willingness to try e-cigarettes, initiation of e-cigarettes and susceptibility to cigarette smoking. ${ }^{25} 2729$ 53-55 Findings specific to adults are more varied but demonstrate that non-menthol flavours in e-cigarettes increase appeal, enjoyment and the price users are willing to pay for the product $^{3032-37}$ and are a primary reason many adults use e-cigarettes. ${ }^{35}$ 42-46 Evidence on whether non-menthol-flavoured e-cigarettes promote or disrupt cessation among adult smokers remains unclear. ${ }^{35} 70-74$

Given that non-menthol flavours available in e-cigarettes attract youth to use these products, the impetus for policymakers to address the issue is strong. Results from the current review make it clear that banning flavours in e-cigarettes would discourage youth use of these products; however, doing so may also discourage adult smokers from using e-cigarettes for smoking cessation. ${ }^{76}$ It is also important to consider the context in which each of these studies was conducted; because this review included results from both USA and global studies, policies may differ and individual cultural contexts around e-cigarette use may have affected the outcomes.

Policy action at the federal level regarding flavoured tobacco products has recently been undertaken, with the FDA seeking to limit the sale of non-menthol-flavoured e-cigarettes to age-restricted locations and heightening age verification practices for products sold online. ${ }^{3}$ Also of note in that same announcement is FDA's consideration of banning menthol in cigarettes, which would significantly impact the tobacco control landscape. ${ }^{3}$ FDA's recent proposed action appears to be affecting manufacturers; the tobacco company Altria recently announced that they would halt the sale of multiple e-cigarette products they produce, including flavoured products, ${ }^{77}$ and Juul Labs also announced a suspension of its non-menthol-flavoured e-cigarettes in retail stores. ${ }^{78}$ In the meantime, states and localities have the authority to restrict the sale of flavoured tobacco products, including flavoured e-cigarettes. A comprehensive review of flavoured e-cigarette regulations from 2017 showed that at the time, over 100 localities had implemented restrictions on the sale of flavoured e-cigarettes. ${ }^{79}$ Movement has continued to be made on this topic since that review; for instance, San Francisco passed a measure to ban the sale of all flavoured tobacco products, ${ }^{80}$ including e-cigarettes, in 2018. Jurisdictions globally have taken steps to more broadly regulate flavours in all tobacco products, recognising their impact on youth. ${ }^{1781}$ This is in accordance with the 2010 WHO Framework Convention on Tobacco Control guidelines that recommend restricting or banning flavours in all tobacco products. ${ }^{82}$

Based on the results of this review, it is important to consider deficits in the literature that would assist policymakers in developing the most impactful regulations. For one, it is important to note that the literature does not have a consistent and standardised way to categorise flavours. Yingst and colleagues ${ }^{83}$ have attempted to identify such a classification system, which, if used by researchers, would allow results to be more easily compared across studies. This would also assist policymakers in regulating flavours more easily, as it is possible that some categories of flavours may be more appealing to youth than others. Similarly, because much of the research uses varying categories to examine age, it makes it difficult to disaggregate the effects flavours have on different age groups. Doing so would especially be helpful to policymakers who are trying to create regulations that would have the most impact on youth initiation while maintaining the potential for adult harm reduction, though more research is needed to explore the latter. Furthermore, use of the QATSDD tool reveals deficits in the existing literature. Few studies provided evidence of sample size consideration or commented on the reliability or validity of their measurement tools. Reviewing these types of parameters before publishing may ensure that researchers are providing the most rigorous explanation of their research as possible. Finally, since so few longitudinal studies are present, it 
may be beneficial for researchers to use such data sets as PATH to show longitudinal trends in the outcomes presented in this review, in an effort to strengthen the existing body of literature with longitudinal data.

\section{Limitations}

Our review is limited in several ways. First, relevant articles may have been missed due to the exclusion of grey literature, doctoral dissertations and non-English language articles; articles published within the search period (before March 2018) may also have been missed if they were not indexed in one of the searched databases by the time of the search. Similarly, we excluded qualitative articles in order to maintain consistency in data reviewed, though we recognise that qualitative data could potentially provide important contextual information on this topic. Second, a minimum threshold for study quality was not set, though only three studies received a score lower than $50 \%$ on the quality assessment (with scores of $48 \%, 45 \%$ and $38 \%$ ), and the mean score of all studies was $66 \%$. Further, three studies were funded or supported by the e-cigarette industry or user advocacy groups. 38571 Findings from these studies, and studies scoring lower in study quality, should be interpreted with caution. Third, more than $90 \%$ of studies were cross-sectional in nature, preventing us from making causal inferences between flavours and the perceptions and use of flavoured e-cigarettes. Future research using longitudinal designs could further elucidate the role of flavours, particularly their effect on behavioural outcomes such as initiation among youth and cessation among adult smokers. Fourth, nearly half of all studies were conducted with convenience samples in the USA, limiting the generalisability of findings, though nearly $40 \%$ of all studies did use probability-based sampling. Lastly, as research on e-cigarette flavours continues to evolve and additional research is regularly published, periodic updates of this review will be needed.

\section{CONCLUSION}

This systematic review provides a necessary update and extension of all evidence published to date on the role of flavours in e-cigarette perceptions and use behaviours. The increasing evidence among youth is clear: flavours in e-cigarettes (particularly sweet flavours) increase product appeal, decrease product harm perceptions and increase willingness to use and initiation of e-cigarettes. Similarly, findings among adults demonstrate that flavours increase product appeal and enjoyment, and the availability of flavours are a primary reason for use for many adults. As the role of e-cigarettes in smoking cessation-and particularly how flavours impact this relationship-remains unclear, longitudinal studies of adult smokers are needed to assess the effect that e-cigarettes may have promoting or disrupting efforts to reduce or quit cigarette use. Regardless, findings are clear that banning flavours in e-cigarettes would discourage youth use of these products.
Contributors $\mathrm{CM}$ and $\mathrm{HMB}$ contributed equally to this paper as joint first authors. $\mathrm{CM}, \mathrm{HMB}$ and SK conducted data review and analysis, drafted the initial manuscript and revised and reviewed the full manuscript. LR and AOG conceptualised the study and provided critical feedback to the intellectual content during drafting and revisions of the manuscript, as well as to the interpretation of data analyses.

Funding The authors have not declared a specific grant for this research from any funding agency in the public, commercial or not-for-profit sectors.

Competing interests None declared.

Patient consent for publication Not required.

Provenance and peer review Not commissioned; externally peer reviewed.

Data availability statement All data relevant to the study are included in the article or uploaded as supplementary information.

Open access This is an open access article distributed in accordance with the Creative Commons Attribution Non Commercial (CC BY-NC 4.0) license, which permits others to distribute, remix, adapt, build upon this work non-commercially, and license their derivative works on different terms, provided the original work is properly cited, appropriate credit is given, any changes made indicated, and the use is non-commercial. See: http://creativecommons.org/licenses/by-nc/4.0/.

\section{REFERENCES}

1 U.S. food and drug administration. menthol and other flavors in tobacco products, 2018. Available: https://www.fda.gov/ tobaccoproducts/labeling/productsingredientscomponents/ ucm2019416.htm [Accessed 24 Jul 2018].

2 U.S. Food and Drug Administration. Statement from FDA commissioner Scott Gottlieb, M.D., on efforts to reduce tobacco use, especially among youth, by exploring options to address the role of flavors - including menthol - in tobacco products, 2018. Available: https://www.fda.gov/NewsEvents/Newsroom/PressAnnouncements/ UCM601690.htm?utm_source=Eloqua\&utm_medium=email\&utm term $=$ StratComms\&utm_content $=$ pressrelease\&utm_campaign $=\bar{C}$ TP News\%26Connect\%26SOS\%3A ANPRM Flavors-32018 [Accessed 9 Oct 2018].

3 U.S. Food and Drug Administration. Statement from FDA commissioner Scott Gottlieb, M.D., on proposed new steps to protect youth by preventing access to flavored tobacco products and banning menthol in cigarettes, 2018. Available: https://www.fda.gov/ news-events/press-announcements/statement-fda-commissionerscott-gottlieb-md-proposed-new-steps-protect-youth-preventingaccess [Accessed 3 May 2019].

4 Huang L-L, Baker HM, Meernik C, et al. Impact of non-menthol flavours in tobacco products on perceptions and use among youth, young adults and adults: a systematic review. Tob Control 2017;26:709-19.

5 Bold KW, Kong G, Camenga DR, et al. Trajectories of e-cigarette and conventional cigarette use among youth. Pediatrics 2018;141:e20171832.

6 Chaffee BW, Watkins SL, Glantz SA. Electronic cigarette use and progression from experimentation to established smoking. Pediatrics 2018;141:e20173594.

7 U.S. Department of Health and Human Services. E-Cigarette use among youth and young adults: a report of the surgeon General. Atlanta, GA, 2016. https://e-cigarettes.surgeongeneral.gov/ documents/2016_sgr_full_report_non-508.pdf

8 Yuan M, Cross SJ, Loughlin SE, et al. Nicotine and the adolescent brain. J Physiol 2015;593:3397-412.

9 England LJ, Bunnell RE, Pechacek TF, et al. Nicotine and the developing human: a neglected element in the electronic cigarette debate. Am J Prev Med 2015;49:286-93.

10 Goniewicz ML, Boykan R, Messina CR, et al. High exposure to nicotine among adolescents who use Juul and other vape pod systems ('pods'). Tob Control 2018;0:1-2.

11 Huang J, Duan Z, Kwok J, et al. Vaping versus JUULing: how the extraordinary growth and marketing of JUUL transformed the US retail e-cigarette market. Tob Control 2018:1-6.

12 Warner KE. Mendez D. e-cigarettes: comparing the possible risks of increasing smoking initiation with the potential benefits of increasing smoking cessation. Nicotine Tob Res 2018:1-7.

13 Hajek P, Phillips-Waller A, Przulj D, et al. A randomized trial of e-cigarettes versus Nicotine-Replacement therapy. $N$ Engl J Med 2019;380:629-37.

14 Beard E, West R, Michie S, et al. Association between electronic cigarette use and changes in quit attempts, success of quit attempts, use of smoking cessation pharmacotherapy, and use of stop 
smoking services in England: time series analysis of population trends. BMJ 2016;354.

15 Bullen C, Knight-West O. Knight-West O. e-cigarettes for the management of nicotine addiction. Subst Abuse Rehabil 2016;7:111-8.

16 McRobbie H, Bullen C, Hartmann-Boyce J, et al. Electronic cigarettes for smoking cessation and reduction (review). Cochrane Libr 2014;12.

17 Kennedy RD, Awopegba A, De León E, et al. Global approaches to regulating electronic cigarettes. Tob Control 2017;26:440-5.

18 Cullen KA, Ambrose BK, Gentzke AS, et al. Notes from the Field: Use of Electronic Cigarettes and Any Tobacco Product Among Middle and High School Students - United States, 2011-2018. MMWR Morb Mortal Wkly Rep 2018;67:1276-7.

19 Mirbolouk M, Charkhchi P, Kianoush S, et al. Prevalence and distribution of e-cigarette use among U.S. adults: behavioral risk factor surveillance system, 2016. Ann Intern Med 2018;169:429.

20 Breland A, Soule E, Lopez A, et al. Electronic cigarettes: what are they and what do they do? Ann N Y Acad Sci 2017;1394:5-30.

21 Zhu S-H, Sun JY, Bonnevie E, et al. Four hundred and sixty brands of e-cigarettes and counting: implications for product regulation. Tob Control 2014;23(suppl 3):iii3-9.

22 U.S. Food and Drug Administration. Family Smoking Prevention and Tobacco Control Act - An Overview, 2018. Available: https://www. fda.gov/tobacco-products/rules-regulations-and-guidance/familysmoking-prevention-and-tobacco-control-act-overview [Accessed 24 Jul 2019].

23 Moher D, Liberati A, Tetzlaff J, et al. Preferred reporting items for systematic reviews and meta-analyses: the PRISMA statement. PLoS Med 2009;6:e1000097.

24 Sirriyeh R, Lawton R, Gardner P, et al. Reviewing studies with diverse designs: the development and evaluation of a new tool. J Eval Clin Pract 2012:18:746-52.

25 Clarke TN, Lusher JM. Willingness to try electronic cigarettes among UK adolescents. J Child Adolesc Subst Abuse 2017;26:175-82.

26 Ford A, MacKintosh AM, Bauld L, et al. Adolescents' responses to the promotion and flavouring of e-cigarettes. Int $J$ Public Health 2016;61:215-24.

27 Pepper JK, Ribisl KM, Brewer NT. Adolescents' interest in trying flavoured e-cigarettes. Tob Control 2016;25(Suppl 2):ii62-6.

28 Cooper M, Harrell MB, Pérez A, et al. Flavorings and perceived harm and Addictiveness of e-cigarettes among youth. tobacco reg sci 2016;2:278-89.

29 Dai H, Hao J. Flavored electronic cigarette use and smoking among youth. Pediatrics 2016;138:e2016513.

30 Audrain-McGovern J, Strasser AA, Wileyto EP. The impact of flavoring on the rewarding and reinforcing value of e-cigarettes with nicotine among young adult smokers. Drug Alcohol Depend 2016;166:263-7.

31 Barnes AJ, Bono RS, Lester RC, et al. Effect of flavors and modified risk messages on e-cigarette abuse liability. tobacco reg sci 2017:3:374-87.

32 Goldenson NI, Kirkpatrick MG, Barrington-Trimis JL, et al. Effects of sweet flavorings and nicotine on the appeal and sensory properties of e-cigarettes among young adult vapers: application of a novel methodology. Drug Alcohol Depend 2016;168:176-80.

$33 \mathrm{Kim} \mathrm{H}$, Lim J, Buehler SS, et al. Role of sweet and other flavours in liking and disliking of electronic cigarettes. Tob Control 2016;25(Suppl 2):ii55-61.

34 Nonnemaker J, Kim AE, Lee YO, et al. Quantifying how smokers value attributes of electronic cigarettes. Tob Control 2016;25:e37-43.

35 Chen JC. Flavored e-cigarette use and cigarette smoking reduction and Cessation-A large national study among young adult smokers. Subst Use Misuse 2018;53:2017-31.

36 Elkalmi R, Bhagavathul A, Ya'u A, et al. Familiarity, perception, and reasons for electronic-cigarette experimentation among the general public in Malaysia: preliminary insight. J Pharm Bioall Sci 2016;8:240-7.

37 Etter J-F. Electronic cigarettes: a survey of users. BMC Public Health $2010 ; 10$.

38 Shiffman S, Sembower MA, Pillitteri JL, et al. The impact of flavor descriptors on nonsmoking teens' and adult smokers' interest in electronic cigarettes. Nicotine Tob Res 2015;17:1255-62.10.1093/ntr/ ntu333

39 Czoli CD, Goniewicz M, Islam T, et al. Consumer preferences for electronic cigarettes: results from a discrete choice experiment. Tob Control 2016;25:e30-6.

40 Lee J, Lee S, Cho H-J. The relation between frequency of e-cigarette use and frequency and intensity of cigarette smoking among South Korean adolescents. Int J Environ Res Public Health 2017; $14: 305$.
41 Tsai J, Walton K, Coleman BN, et al. Reasons for electronic cigarette use among middle and high school students - national youth tobacco survey, United States, 2016. MMWR Morb Mortal Wkly Rep 2018;67:196-200.

42 Amato MS, Boyle RG, Levy D. How to define e-cigarette prevalence? finding clues in the use frequency distribution. Tob Control 2016;25:e24-9.

43 Coleman BN, Rostron B, Johnson SE, et al. Electronic cigarette use among US adults in the population assessment of tobacco and health (path) study, 2013-2014. Tob Control 2017;26:e117-26.

44 Spears CA, Jones DM, Weaver SR, et al. Motives and perceptions regarding electronic nicotine delivery systems (ends) use among adults with mental health conditions. Addict Behav 2018;80:102-9.

45 Gubner NR, Pagano A, Tajima B, et al. A comparison of daily versus Weekly electronic cigarette users in treatment for substance abuse. Nicotine Tob Res 2018;20:636-42.

46 Berg CJ. Preferred flavors and reasons for e-cigarette use and discontinued use among never, current, and former smokers. Int $J$ Public Health 2016;61:225-36.

47 Maglalang DD, Brown-Johnson C, Prochaska JJ. Associations with e-cigarette use among Asian American and Pacific Islander young adults in California. Preventive Medicine Reports 2016;4:29-32.

48 Patel D, Davis KC, Cox S, et al. Reasons for current E -cigarette use among U.S. adults. Prev Med 2016;93:14-20.

49 Rutten LJF, Blake KD, Agunwamba AA, et al. Use of e-cigarettes among current smokers: associations among reasons for use, quit intentions, and current tobacco use. NICTOB 2015;17:1228-34.

50 Harrell MB, Weaver SR, Loukas A, et al. Flavored e-cigarette use: characterizing youth, young adult, and adult users. Prev Med Rep 2017;5:33-40.

51 Shiplo S, Czoli CD, Hammond D. E-Cigarette use in Canada: prevalence and patterns of use in a regulated market. BMJ Open 2015:5:e007971-7.

52 Pepper JK, Reiter PL, McRee A-L, et al. Adolescent males' awareness of and willingness to try electronic cigarettes. $J$ Adolesc Health 2013;52:144-50.

53 Bold KW, Kong G, Cavallo DA, et al. Reasons for trying e-cigarettes and risk of continued use. Pediatrics 2016;138. doi:10.1542/ peds.2016-0895

54 Chen JC, Das B, Mead EL, et al. Flavored e-cigarette use and cigarette smoking susceptibility among youth. tobacco reg sci 2017;3:68-80.

55 Vasiljevic M, Petrescu DC, Marteau TM. Impact of advertisements promoting candy-like flavoured e-cigarettes on appeal of tobacco smoking among children: an experimental study. Tob Control 2016;25:e107-12.

56 Brożek G, Jankowski M, Zejda J, et al. E-smoking among students of medicine - frequency, pattern and motivations. Adv Respir Med 2017;85:8-14.

57 Kinouani S, Pereira E, Tzourio C. Electronic cigarette use in students and its relation with tobacco-smoking: a cross-sectional analysis of the I-Share study. Int J Environ Res Public Health 2017;14:1345.

58 Farsalinos K, Romagna G, Tsiapras D, et al. Characteristics, perceived side effects and benefits of electronic cigarette use: a worldwide survey of more than 19,000 consumers. Int J Environ Res Public Health 2014;11:4356-73.

59 Pepper J, Ribisl K, Emery S, et al. Reasons for starting and stopping electronic cigarette use. Int J Environ Res Public Health 2014:11:10345-61.

60 Lee H-Y, Lin H-C, Seo D-C, et al. Determinants associated with e-cigarette adoption and use intention among college students. Addict Behav 2017:65:102-10.

61 Russell C, McKeganey N, Dickson T, et al. Changing patterns of first e-cigarette flavor used and current flavors used by 20,836 adult frequent e-cigarette users in the USA. Harm Reduct J 2018;15:33.

62 Kong G, Morean ME, Cavallo DA, et al. Reasons for electronic cigarette experimentation and discontinuation among adolescents and young adults. Nicotine Tob Res 2015;17:847-54.

63 Shang C, Huang J, Chaloupka FJ, et al. The impact of flavour, device type and warning messages on youth preferences for electronic nicotine delivery systems: evidence from an online discrete choice experiment. Tob Control 2017;0:1-8.

64 Krishnan-Sarin S, Morean ME, Camenga DR, et al. E-Cigarette use among high school and middle school adolescents in Connecticut. Nicotine Tob Res 2015;17:810-8.

65 Yingst JM, Veldheer S, Hrabovsky S, et al. Factors associated with electronic cigarette users' device preferences and transition from first generation to advanced generation devices. NICTOB 2015;17:1242-6.

66 Buckell J, Marti J, Sindelar JL. Should flavours be banned in cigarettes and e-cigarettes? evidence on adult smokers and recent 
quitters from a discrete choice experiment. Tob Control 2018. doi:10.1136/tobaccocontrol-2017-054165

67 Pesko MF, Kenkel DS, Wang H, et al. The effect of potential electronic nicotine delivery system regulations on nicotine product selection. Addiction 2016;111:734-44.

68 Morean ME, Butler ER, Bold KW, et al. Preferring more e-cigarette flavors is associated with e-cigarette use frequency among adolescents but not adults. PLoS One 2018;13.

69 Harrell M, Loukas A, Jackson C, et al. Flavored Tobacco Product Use among Youth and Young Adults: What if Flavors Didn't Exist? tobacco reg sci 2017;3:168-73.

70 Litt MD, Duffy V, Oncken C. Cigarette smoking and electronic cigarette vaping patterns as a function of e-cigarette flavourings. Tob Control 2016;25(Suppl 2):ii67-72.

71 Farsalinos K, Romagna G, Tsiapras D, et al. Impact of flavour variability on electronic cigarette use experience: an Internet survey. Int J Environ Res Public Health 2013;10:7272-82.

72 Etter J-F. Characteristics of users and usage of different types of electronic cigarettes: findings from an online survey. Addiction 2016;111:724-33.

73 Weaver SR, Huang J, Pechacek TF, et al. Are electronic nicotine delivery systems helping cigarette smokers quit? Evidence from a prospective cohort study of U.S. adult smokers, 2015-2016. PLoS One 2018;13:e0198047.

74 Tackett AP, Lechner WV, Meier E, et al. Biochemically verified smoking cessation and vaping beliefs among vape store customers. Addiction 2015;110:868-74

75 Camenga DR, Kong G, Cavallo DA, et al. Current and former smokers' use of electronic cigarettes for quitting smoking: an exploratory study of adolescents and young adults. Nicotine Tob Res 2017:19:1531-5.
76 U.S. Food and Drug Administration. Statement from FDA commissioner Scott Gottlieb, M.D., on new steps to address epidemic of youth e-cigarette use, 2018. Available: https://www.fda. gov/NewsEvents/Newsroom/PressAnnouncements/ucm620185.htm [Accessed 26 Oct 2018].

77 Bomey N. Marlboro maker Altria stops sales of flavored vaping liquid. USA today, 2018. Available: https://www.usatoday.com/story/ money/2018/10/25/altria-group-flavored-vaping-liquid/1759794002/ [Accessed 25 Oct 2018].

78 Kaplan S, Hoffman J. Juul suspends Selling most e-cigarette flavors in stores. New York times, 2018. Available: https://www. nytimes.com/2018/11/13/health/juul-ecigarettes-vaping-teenagers. html

79 Chen JC, Green KM, Chen J, et al. Restricting the sale of flavored e-cigarettes in the US: an examination of local regulations. tobacco reg sci 2018;4:32-40.

80 Hoffman J. San Francisco voters Uphold ban on flavored Vaping products. NY times, 2018. Available: https://www.nytimes.com/ 2018/06/06/health/vaping-ban-san-francisco.html [Accessed 9 Oct 2018].

81 Campaign for Tobacco-Free Kids. Brazil's Highest Court Upholds Ban on Flavored Tobacco Products, 2018. Available: https://www. tobaccofreekids.org/press-releases/2018_02_01_brazil-courtupholds-flavor-ban [Accessed 24 Jul 2018].

82 World Health Organization. Partial guidelines for implementation of articles 9 and 10 of the who framework convention on tobacco control, 2012. Available: http://www.who.int/fctc/guidelines/ Guideliness_Articles_9_10_rev_240613.pdf

83 Yingst JM, Veldheer S, Hammett E, et al. A method for classifying user-reported electronic cigarette liquid flavors. Nicotine Tob Res 2017;19:ntw383-5. 